\title{
LA EXTENSIÓN DE LOS EFECTOS DEL CONVENIO ARBITRAL A NO SIGNATARIOS. REFLEXIONES CON MOTIVO DEL TRATAMIENTO QUE LA NUEVA LEY PERUANA DE ARBITRAJE EFECTÚA A DICHA FIGURA
}

\author{
Natale Amprimo Plá*
}

\begin{abstract}
Resumen
El convenio arbitral constituye la piedra angular de todo arbitraje; $y$, a efecto de demostrar su existencia, las diferentes normas que regulan el arbitraje en el mundo exigen, en su mayoría, que dicho acuerdo conste por escrito; pero las modalidades de cumplimiento del requisito de la forma escrita se han ido ampliando, al punto que hoy no se discute que cualquier medio que permita generar una "constancia de acuerdo" es suficiente para que se considere cumplido el mismo.
\end{abstract}

Ahora bien, independientemente de esas modalidades, hay casos en los que, tanto doctrinaria como jurisprudencialmente, se admite que sujetos que no han sido parte stricto sensu del acuerdo arbitral, sean obligados a participar del proceso arbitral. El legislador peruano recoge una opción novedosa de esta posibilidad en la Ley Peruana de Arbitraje (artículo $14^{\circ}$ del Decreto Legislativo $\mathrm{N}^{\circ}$ 1071).

Palabras clave: Arbitraje - Convenio arbitral - Constancia de acuerdo - Buena fe.

\begin{abstract}
The arbitration agreement is the cornerstone of any and all arbitration proceedings; and, with the aim of proving its existence, the majority of the different rules that regulate arbitration proceedings in the world require that the referred agreement be in writing. However, the modalities for the fulfillment of this requirement have been gradually extended, to such a point that presently, there is no discussion about the fact that any means that produces a "testimony of the agreement" is enough for it to be considered fulfilled.
\end{abstract}

Independently from these modalities, there are cases in which, both the doctrine and case law admit that those individuals who are not a party, in the strict sense, to the arbitration agreement, are obliged to participate in the arbitration proceeding. The Peruvian legislator adopts an innovative option of this possibility in the Peruvian Arbitration Law (Article $14^{\circ}$ of Legislative Decree $\mathrm{N}^{\circ}$ 1071).

* Profesor de Derecho Constitucional en la Facultad de Derecho de la Universidad de Lima. 
Key words: Arbitration - Arbitration Agreement - Testimony of Agreement - Good faith.

\section{Sumario}

1. Introducción. 2. Constancia del contenido del convenio arbitral.

3. Consentimiento en el convenio arbitral. 4. Extensión del convenio arbitral en el Perú.

\section{INTRODUCCIÓN}

El arbitraje, como mecanismo de solución de controversias eminentemente privado, encuentra su origen y razón de ser en la voluntad de las partes, las que libérrimamente renuncian al mecanismo natural de solución de conflictos que les provee el Estado y le confieren autoridad al árbitro designado, para que sea este último quien resuelva el desacuerdo o conflicto.

Esa voluntad de las partes, expresada en lo que se conoce como "convenio arbitral", no puede tener eficacia ni producir efectos respecto de quienes no han prestado su consentimiento, pues como se sabe, por ser un principio universalmente conocido, "[los] contratos sólo producen efectos entre las partes que las otorgan y sus herederos, salvo en cuanto a éstos si se trata de derechos y obligaciones no transmisibles"1 ${ }^{1}$. Como indica Caivano, este principio, aplicado al caso del convenio arbitral en particular, "[...] tiene como propósito evitar que alguien, sin haber expresado su consentimiento, sea forzado a dirimir determinadas controversias por arbitraje, siendo paralelamente obligado a resignar la competencia de los tribunales judiciales" ${ }^{\prime 2}$.

\section{CONSTANCIA DEL CONTENIDO DEL CONVENIO ARBITRAL}

Así, el convenio arbitral constituye la piedra angular de todo arbitraje; $\mathrm{y}^{3}$, a efectos de demostrar su existencia, las diferentes normas que regulan el arbitraje en el mundo exigen, en su mayoría, que el acuerdo arbitral conste por escrito, aún cuando, acto seguido, contemplan diversas modalidades de constancia escrita, llegándose incluso a flexibilizar el cumplimiento de este requisito a los convenios arbitrales pactados en soportes que dejen constancia no necesariamente escrita de su contenido, pero que sean accesibles para su ulterior consulta ${ }^{4}$.

De esta forma, la mayoría de la legislación comparada sigue la Ley Modelo elaborada por la Comisión de las Naciones Unidas para el Desarrollo Mercantil Internacional (conocida como Ley Modelo CNUDMI o UNCITRAL) que, 
en la Opción I de su artículo $7^{\circ}$, señala que "Se entenderá que el acuerdo es escrito cuando quede constancia de su contenido en cualquier forma, ya sea que el acuerdo de arbitraje o contrato se haya concertado verbalmente, mediante la ejecución de ciertos actos o por cualquier otro medio" (apartado 3), y que "El requisito de que un acuerdo de arbitraje conste por escrito se cumple con la comunicación electrónica si la información en ella consignada es accesible para su ulterior consulta. Por 'comunicación electrónica' se entenderá toda comunicación que las partes hagan por medio de mensajes de datos. Por 'mensaje de datos' se entenderá la información generada, enviada, recibida o archivada por medios electrónicos, magnéticos, ópticos o similares, como pudieran ser, entre otros, el intercambio electrónico de datos, el correo electrónico, el telegrama, el télex o el telefax" (apartado 4$)^{5}$.

En ese sentido, como consecuencia de la evolución del tráfico negocial y del avance de la tecnología, que en materia de comunicaciones ha generado una auténtica revolución, impactando sin lugar a dudas en el derecho de los contratos, se han ido ampliando las modalidades de cumplimiento del requisito de la forma escrita del convenio arbitral, al punto que hoy no se discute que cualquier medio que permita generar una "constancia de acuerdo" es suficiente para que se considere cumplido el requisito de la constancia por escrito ${ }^{67}$. Como expresa Caivano, "[el] documento electrónico consiste, fundamentalmente, en la fijación de información en un soporte electrónico (u óptico), que queda registrada en la memoria auxiliar del computador. En sentido estricto, es el documento que aparece instrumentado sobre la base de impulsos electrónicos y no sobre un papel, y conservado en forma digital en la memoria del ordenador a través de sus propios órganos de salida, que es perceptible por el hombre sin intervención de máquinas traductoras. El documento electrónico es reconocido, mayoritariamente, como perteneciente al género más amplio de 'documento', concebido como 'toda representación objetiva de un pensamiento', como todo objeto que pueda informar sobre un hecho o un acto con consecuencias jurídicas, sin ceñirse a la escritura (grafía) ni a la naturaleza del soporte (papel). El documento electrónico, en suma, supone la ruptura de la clásica trilogía 'papel-escrito-firma', que ha sido cimiento de la cultura jurídica de la antigüedad"8.

\section{CONSENTIMIENTO EN EL CONVENIO ARBITRAL}

Ahora bien, independientemente de las modalidades que hoy la legislación reconoce como demostrativas de la existencia de un convenio arbitral, hay casos en los que, tanto doctrinaria como jurisprudencialmente, se admite que sujetos que no han sido parte stricto sensu del acuerdo arbitral, sean obligados 
a participar en el proceso arbitral ${ }^{9}$. Es decir, casos en los que se produce la extensión de la cláusula arbitral a no signatarios de esta última.

Sobre esto último, hay que precisar que en la práctica del arbitraje internacional no es extraño, por ejemplo, que el tribunal arbitral deba analizar si un acuerdo arbitral celebrado por una sociedad pueda obligar al grupo de sociedades vinculadas con ella, debido a que en el mundo moderno se presenta cada vez más el caso de relaciones económicas en las que las partes están constituidas a su vez por redes de relaciones ${ }^{10}$. Como explica De Trazegnies:

“Tanto en el ámbito internacional como en el nacional pueden encontrarse situaciones tales como que un grupo económico extranjero obtiene la buena pro para desarrollar una obra dentro de las fronteras de un determinado Estado y, para este efecto, utiliza una u otra de las compañías que integran el grupo, según criterios de especialidad o de oportunidad; y sucede que el dueño de la obra puede intentar reclamar por defectos en ella contra no necesariamente aquella empresa que la ejecutó directamente y que tiene un patrimonio reducido sino sobre la más importante de las compañías de ese grupo empresarial aunque no haya participado o haya tenido una participación sólo incidental en la obra. Las relaciones financieras asumen también en algunos casos formas muy complejas en las que intervienen muchas personas jurídicas de una y otra parte; y puede suceder que los accionistas de una sociedad invoquen el convenio arbitral estatutario para demandar a otras compañías del grupo mayoritario y reclamar sobre el patrimonio que, a través de una red de subsidiarias, pretenden que les habría sido escamoteado.

\section{$[\ldots]$}

Es así como, desde hace algún tiempo, la doctrina y la jurisprudencia de algunos países y tribunales arbitrales internacionales ha tentado, cautelosa pero valerosamente, el camino espinoso de ver más allá de las formas jurídicas para resolver los conflictos de manera más conforme con la realidad. El descorrimiento del velo societario es una institución nueva, destinada a evitar que, detrás de un formalismo jurídico que cumple un papel de escudo, se desarrollen actividades que perjudican a ciertos accionistas de la sociedad o a terceros vinculados con algún tipo de contrato. Para llegar a este punto, se ha creado la teoría del "grupo de sociedades" - también llamada del 
alter ego o del rasgado o descorrimiento del velo societario (piercing the corporate veil) o, por último, como la teoría del disregard - que permite ver el conjunto de los intereses y relaciones económicas reales que existen detrás de la forma societaria"11.

\section{EXTENSIÓN DEL CONVENIO ARBITRAL EN EL PERÚ}

En ese sentido, es de suma importancia para la comunidad jurídica vinculada al arbitraje, la forma como la novísima Ley peruana de Arbitraje ${ }^{12}$ aborda, en su artículo $14^{\circ}$, lo relativo a la extensión de los efectos del convenio arbitral a no signatarios.

Así, el referido artículo $14^{\circ}$, titulado "Extensión del convenio arbitral", preceptúa que "El convenio arbitral se extiende a aquellos cuyo consentimiento de someterse a arbitraje, según la buena fe, se determina por su participación activa y de manera determinante en la negociación, celebración, ejecución o terminación del contrato que comprende el convenio arbitral o al que el convenio esté relacionado. Se extiende también a quienes pretendan derivar derechos o beneficios del contrato, según sus términos".

Creemos que la opción elegida por el legislador peruano resulta novedosa, pues contempla la posibilidad, de manera expresa, que el convenio se extienda a quienes no lo han suscrito, si es que de su conducta se puede derivar, de buena fe, su intención de someterse al arbitraje.

En buena cuenta, el artículo $14^{\circ}$ de la Ley Peruana de Arbitraje reconoce la existencia de una manifestación de voluntad tácita de someterse al arbitraje, según el principio de buena fe, lo que resulta acorde con el artículo $1362^{\circ}$ del Código Civil peruano de 1984, que dispone que "Los contratos deben negociarse, celebrarse y ejecutarse según las reglas de la buena fe y común intención de las partes", lo que, como comentó en su oportunidad Arias Schereiber, se basa en el concepto "[...] de que la ley no debe tener rigor formalista, sino un alto contenido moral. De allí las referencias al hecho de que su negociación, celebración y ejecución están sujetas a las reglas de la buena fe y común intención de las partes, que son las que inspiran la relación obligacional"13.

Por tanto, el legislador peruano ha considerado que si de la conducta de las partes se infiere una declaración tácita de voluntad, no sería acorde al principio de buena fe subordinar los efectos de la referida manifestación de voluntad tácita, a la exigencia de una formalidad escrita. Es evidente que el legislador ha tenido que incorporar una disposición específica en la Ley de 
Arbitraje respecto de los efectos de la manifestación de voluntad tácita al convenio arbitral, habida cuenta que el artículo $141^{\circ}$ del Código Civil peruano preceptúa:

“Artículo $141^{\circ}$.- La manifestación de voluntad puede ser expresa o tácita. Es expresa cuando se realiza en forma oral o escrita, a través de cualquier medio directo, manual, mecánico, electrónico u otro análogo. Es tácita, cuando la voluntad se infiere indubitablemente de una actitud o de circunstancias de comportamiento que revelan su existencia.

No puede considerarse que existe manifestación tácita cuando la ley exige declaración expresa o cuando el agente formula reserva o declaración en contrario".

Respecto a la buena fe, habría que decir, siguiendo a Campagnucci De Caso, que ésta "[...] tiene un contenido preceptivo que muestra su propia exorbitancia sobre la voluntad de los contratantes, y se sitúa por encima de ellos. Son estos quienes en sus comportamientos y conductas deben adecuarse a la regla, y de ninguna manera se puede dar el sentido inverso. Significa, ni más ni menos, obligarse a la fidelidad a la palabra empeñada, y no abusar ni defraudar la confianza en que se basó la relación"14.

En ese sentido, coincidiendo con lo señalado por Cantuarias Salaverry y Caivano, creemos que el artículo $14^{\circ}$ de la Ley peruana de Arbitraje no rompe con el principio básico conforme al cual el arbitraje es estrictamente privado, pues ello no es contradictorio con admitir que, dadas ciertas circunstancias de hecho particulares, es posible considerar que alguien ha expresado su conformidad a someterse a arbitraje, aún en ausencia de una expresa y formal aceptación. Así, la Ley peruana de Arbitraje, priorizando “[...] la realidad por sobre la forma o mera apariencia, [...] reconoce - en sintonía con la ampliación del concepto convenio arbitral escrito que hemos comentado - que la firma puesta en el instrumento no es la única forma de prestar el consentimiento para someterse a arbitraje. Dicho de otra manera: el solo hecho de que alguien no haya sido firmante directo del convenio arbitral no impide que, con base en la buena fe y tomando en cuenta la participación que - de hechohubiese tenido en el contrato o su pretensión de invocar derechos o beneficios derivados del mismo, pueda verse obligado por sus efectos. La norma en comentario, con una lógica impecable, sólo predica que la mera circunstancia de no haber sido - en sentido formal - parte en el acuerdo arbitral no significa - necesariamente - un impedimento para invocar el convenio arbitral o para 
que éste sea oponible. Aunque, claro está, ello requerirá la demostración de ciertos presupuestos de hecho que la misma norma señala"15.

De esta forma, no es que a la luz del artículo $14^{\circ}$ de la Ley peruana de Arbitraje, el tribunal arbitral va a inventar un convenio arbitral entre quienes no lo han celebrado. Se trata de que, en palabras de De Trazegnies, el tribunal no cierre los ojos "[...] frente a los casos en que ese acuerdo se hubiera consumado si el asunto no hubiera sido tan complejo y las posibilidades de creación e intervención de subsidiarias no hubiere pasado desapercibida para alguna de las partes, en contra de lo que representaba la verdadera intención de éstas: el negocio en el cual querían intervenir comprendía más aspectos y más personas jurídicas de los que les fueron presentados al momento de ingresar al negocio sometido a un convenio arbitral"16.

En consecuencia, extender el convenio arbitral a no signatarios vinculados al grupo económico celebrante del contrato, que participaron activa y de manera preponderante, en la negociación, celebración, ejecución o terminación del contrato que comprende el convenio arbitral o al que el convenio esté relacionado, o a quienes pretendan derivar derechos o beneficios de aquel, se ajusta a la verdadera intención de las partes, por lo que mal se podría, respetando el principio de buena fe, asumir un criterio restrictivo que incluso, en algunos casos, podría implicar además la consumación de un abuso de derecho.

Sin lugar a dudas, pronto veremos como el artículo $14^{\circ}$ de la Ley peruana de Arbitraje es recogido por la legislación de otros países, muchos de los que, incluso, tienen una mayor tradición arbitral. El legislador peruano ha dado un paso más en la línea correcta del desarrollo del arbitraje en los inicios del siglo XXI.

\footnotetext{
Artículo $1363^{\circ}$ del Código Civil peruano de 1984.

2 Caivano, Roque J. «Arbitraje y grupos de sociedades. Extensión de los efectos de un acuerdo arbitral a quien no ha sido signatario». Revista Lima Arbitration. Editada por el Círculo Peruano de Arbitraje. $N^{\circ} 1$. Disponible en internet: http://www.limaarbitration.net/; Lima, 2006, p. 122.

3 Gonzáles De Cossío, Francisco. Arbitraje. Segunda edición. México: Editorial Porrúa, 2008, p. 55.

4 Con lo que el medio para probar la existencia del convenio arbitral dejó de ser un requisito ad solemnitatem y pasa a ser uno ad probationem.

5 Véase el artículo $13^{\circ}$ de la Ley peruana de Arbitraje, Decreto Legislativo No 1071.

6 Redfern, Alan; Hunter, Martin; Blackaby, Nigel; y Partasides, Constantine; Teoría y práctica del arbitraje comercial internacional. Navarra: Editorial Aranzadi S.A., 2006, p. 224.

7 Además, no debe olvidarse que el apartado 5 de la Opción I del artículo $7^{\circ}$ de la Ley Modelo UNCITRAL considera que se entiende que el arbitraje es escrito "[...] cuando esté consignado en un intercambio de escritos de demanda y contestación en los que la existencia de un acuerdo sea afirmada por una parte sin ser negada por la otra". Texto similar asume el apartado 5 del artículo $13^{\circ}$ de la Ley peruana de Arbitraje.
} 
8 Caivano, Roque J. La cláusula arbitral. Evolución histórica y comparada. Bogotá: Editorial Universidad del Rosario, 2008, pp. 328 - 329.

9 Caivano, Roque J. Arbitraje y grupos..., p. 123.

10 El caso "Dow Chemical c. Isover Saint Gobain" constituye la doctrina principal en lo que se refiere a la teoría del "grupo empresario". En este caso, tramitado ante un tribunal CCI, se planteó un reclamo no solo por las empresas que habían celebrado los acuerdos correspondientes sino también por la sociedad matriz estadounidense y una sociedad controlada francesa integrante del mismo grupo. Cuando el tribunal arbitral, presidido por el profesor Sanders, hizo el análisis de las circunstancias en las que se había celebrado en contrato principal, determinó que Dow Chemical Company (USA), que era la sociedad matriz, era la que ejercía "el control societario absoluto sobre las sociedades controladas que habían suscrito los contratos pertinentes o que, como en Dow Chemical France, había participado efectiva e individualmente de su celebración, cumplimiento y extinción". Incluso se determinó que había una cláusula por la que las entregas podría realizarlas cualquier sociedad controlada o de propiedad de Dow Chemical Company (USA), demostrándose, de esta forma, que esta última era el eje central de la relación contractual finalmente establecida entre ciertas entidades del grupo y los distribuidores. Léase Redfern, Alan; Hunter, Martin; Blackaby, Nigel; y Partasides, Constantine. Op. Cit., pp. 241 y 242.

11 De Trazegnies Granda, Fernando. «El rasgado del velo societario dentro del arbitraje». Revista Ius et Veritas. Revista editada por estudiantes de la Facultad de Derecho de la Pontificia Universidad Católica del Perú. Año XIV. N²9. Lima, 2004, p. 12.

12 El Decreto Legislativo $\mathrm{N}^{\circ} 1071$ entró en plena vigencia recién el $1^{\circ}$ de setiembre de 2008.

13 Arias Schreiber, Max; «Exposición de motivos y comentarios. Contratos en general». En: en Código Civil. Exposición de Motivos y Comentarios. Comisión encargada del Estudio y Revisión del Código Civil", cuya compiladora fue la doctora Delia Revoredo Marsano. Tomo VI. Okura Ediciones S.A. Lima, 1985, p. 25.

${ }^{14}$ Campagnucci De Caso, Rubén H.; «El principio de la buena fe en las relaciones jurídicos de derecho privado». En: Tratado de la Buena Fe en el Derecho. Bajo la dirección de Marcos M. Córdoba. Tomo I. Buenos Aires: Editorial La Ley, 2005, p. 174.

15 Cantuarias Salaverry, Fernando y Caivano, Roque J. «La Nueva Ley de Arbitraje Peruana: Un nuevo salto a la modernidad». Revista Peruana de Arbitraje. N 7/2008. Lima: MAGNA ediciones, 2008, pp. 60-61.

${ }_{16}$ De Trazegnies Granda, Fernando. Ob. Cit., p. 19. 